\title{
Profile of Refractive Errors Among Mansoura University Students
}

Tharwat H. Mokbel, Ahmad Mousa, Eman Elhefney, Manal A. Kasem, Marwa ElKhattabi, Shereen A.AbdAllah, Ahmed Alnagdy, Doaa Shokry

Ophthalmology department, Faculty of Medicine, Mansoura University, Mansoura

Correspondence to: Tharwat Mokbel. Ophthalmology Center, Faculty of Medicine, Mansoura University, Mansoura , PO.35516,Egypt.Email: tharwatmokbel@yahoo.com

Received: 27-12-2020, Accepted: 24-5-2021, Published online:10-6-2021

EJO(MOC) 2021;2:58-69.

Running title: Mansoura University Students’ Refractive Errors

\begin{abstract}
Introduction: To assess the prevalence of refractive errors, identifying the associated factors, and to correlate demographic characteristics (sex, and family history) with different types of refractive errors among Mansoura University students.

Methods: A descriptive cross-sectional study included 400 students from Mansoura university students including both practical and theoretical faculties during the year 2019. The recruited sample was attending to Students' Hospital, Mansoura University. All included students underwent measurement of uncorrected (UCVA), and the best corrected visual acuity (BCVA) in decimal notation. Cycloplegic objective refraction was measured using auto-refractometer with cyclopentolate 1\% (Alcon). A questionnaire was used to detect Socio-demographic characteristics of studied students (age, gender, academic year, and residency), Medical History, comorbidities, and refractive errors history (family history of refractive error, wearing glasses/contact lenses, and duration of use).

Results: Myopia was found in (34\%) of the students. The most prevalent type of myopia was low myopia (75\%). Hyperopia was found in $(3 \%)$ of the students. Astigmatism was found in $(39 \%)$ of students. The majority of students with refractive errors were female accounted for (50.4\%), while males accounted for (49.6\%). The rural to urban errors prevelance was not significant $(51.9 \%, 48.1 \%$ respectively). The medical faculties showed the highest prevalence of refractive errors $(34.1 \%)$, followed by Engineering, Computer science, and Education (15.5\%), (14.4\%) respectively-

Conclusion: The highest rates of errors among Mansoura university students were myopia and astigmatism specially at medical colleges. The profile of refractive status of that specific population needs further attention, as long-term vision impairment will face the future adult population unless specific actions are taken.
\end{abstract}

Keywards: Astigmatism, Hyperopia, Mansoura University Students, Myopia, Prevalence, Refractive Errors.

\footnotetext{
Egyptian Journal of Ophthalmology, a publication of Mansoura Ophthalmic Center.

Address: Mansoura Ophthalmic Center, Mansoura University, Mansoura, Egypt.

Website: https://ejomos.journals.ekb.eg

Tel. 0020502202064. Fax. 0020502202060.

E-mail: ejo@mans.edu.eg
} 


\section{Introduction}

Refraction errors (RE) constitutes the primary cause of visual affection, and considered to be the second cause of eye morbidity all over the globe. ${ }^{1,2}$ The prevalence of such RE is increasing significantly and there is a prediction that myopic individuals will increase up to 3352 millions by the year 2050 . Thus, the number of people with visual impairment due to refractive errors would be estimated at 6.8 millions. $^{3}$

The global distribution of myopia varies, although genetics plays an important role, it does not explain the higher prevalence among younger generations specially, educated students. ${ }^{4}$ Therefore, environmental factors are believed to have an effective role in the etiology of myopia. On the other hand, some studies reported lower myopic progression among those who have outdoor activities. ${ }^{5-8}$ Nevertheless, there is a lack for studies that tackle the prevalence of myopia in the Middle East. Additionally, a meta-analysis study reported that the number of blind cases due to cataract (which is the primary cause for blindness) has decreased from 1990 to 2010 in the Middle East and North Africa, while blindness due to uncorrected refractive errors have drastically increased. Moreover, it was found that uncorrected refractive errors with cataract are the most effective factor causing moderate to severe visual impairment in $2010 .^{9}$

Refractive errors in Egypt are of the major health problems that are linked to environmental risk factors such as socioeconomic level, heavy traffic, and environmental pollution. nonetheless, there are few studies demonstrating its prevalence. $^{10,11}$

This study aimed to assess the prevalence of refractive errors, identifying the associated risk factors, and to correlate personal characteristics (age, sex and family history) with different types of refractive errors among Mansoura University students, Dakahlia governorate, Egypt.

\section{Subjects and methods}

This study was a descriptive cross-sectional study, that was carried out during the year

2019.

\section{Target population:}

The target population was Mansoura university students including both practical and theoretical faculties during the year 2019 where all recruited students were attending to Students' Hospital- Mansoura University.

\section{Sample Size calculation:}

The sample size of this study was 383 participants (at 95\% confidence intervals, and $80 \%$ Study power).

The sample size was increased to 400 participants to increase the study power and account for potential drop outs.

Data were collected via a semi-structured questionnaire, which included the following:

-Socio-demographic characteristics of studied students.

-Medical History, and co morbidities.

-Assessment of Frequency of errors of refraction by Nidek$310 \mathrm{~A}$

The protocol of this study was approved by IRB of Mansoura UNiversity. Consent was obtained from each participant sharing in the study. Personal privacy and confidentiality were maintained through all levels of the study.

\section{Statistical analysis}

Analyzing the data was done using the Statistical Package of Social Science (SPSS) program (version 24). One-sample Kolmogorov-Smirnov test was used to test the normality of the data. Qualitative data were described using number and percent. Association between categorical variables was tested using Chi-square test, while Monte carlo test was used when expected cell count less than 5. Continuous variables were presented as mean $\pm \mathrm{SD}$ (standard deviation). P values less than $0.05(5 \%)$ was considered to be statically significant. 


\section{Clinical Examinations}

All students underwent measurement of uncorrected, and the best corrected visual acuity (BCVA) in decimal, using Nidek auto chart projector CP-670 bearing the tumbling Eopto type. Cycloplegic refraction was measured in all students using the Nidek 310-A autorefractometer, cycloplegia obtained by using cyclopentolate $1 \%$

(Alcon), twice instillation, with interval 10 minutes in between the two instillations, then the refraction was obtained 30 minutes from the last instillation. Complete ocular examination was done to assess anterior and posterior segments of the eye, using slit- lamp biomicroscopy (Slit Lamp HaagStreit BM 900, Haag- Streit, Bern, Switzerland), and direct ophthalmoscopy (HEINE BETA 200 ophthalmoscopy, HEINE Optotechnic, Germany)

In this study spherical equivalent (SE) that based on cycloplegic refraction was used to detect refractive errors. SE was calculated by the standard formula (the algebraic sum of the dioptric powers of the sphere and half of the cylinder). Eyes of patients which found myopic in one eye and emmetropic, hyperopic or astigmatic in the fellow eye, (s) was considered myopic.

Myopia and hyperopia were defined as a SE equal to or worse than-0.5 D and $+0.5 \mathrm{D}$, respectively, Myopes were further divided into three refractive error sub-groups (that were based on their refractive SE); low myopia (SE between- 0.50 and - 2.99 D), moderate myopia (SE between -3.00 and -5.99 D), and high myopia SE (SE $\geq-6.00 \mathrm{D})$. Hyperopes were also divided into three refractive error sub-groups (that were based on their refractions SE); low hyperopia (SE between 0.00 to $+3.00 \mathrm{D}$ ), moderate hyperopia (SE between +3.12 to +4.99D) and High hyperopia $(\mathrm{SE} \geq+5.00 \mathrm{D})$. Astigmatism was defined as a cylinder power worse than $0.5 \mathrm{D}$. Anisometropia was defined as a SE difference of at least $1 \mathrm{D}$ between two eyes. Amblyopia is considered if there was a unilateral or bilateral BCVA of 0.6 decimal or less, or if there was at least two visual acuity lines difference between the two eyes without detected any ocular pathology. Amblyopic depth is classified as mild (from 1.00 to 0.50 decimal), moderate (from 0.50 to 0.25 decimal), and severe amblyopia (worse than 0.25 decimal).

\section{Results}

Socio-demographic data and clinical characteristics are shown in (table1), the study included 400 students who attended to Students hospital. As regards age, mean (SD) age of students was 20.35 (1.21) ranged from 18 to 23 years old. 48 $\%$ of them were males and $52 \%$ were females, $48.5 \%$ from urban residence and $51.5 \%$ from rural areas.

As regards distribution of students according to colleges, 129 students $(32.2 \%)$ were from medical colleges, $13(3.2 \%)$ from Science, 66 (16.5\%) from Engineering, and Computer science, 37 (9.2\%) from Commerce, 19 (4.8\%) from Agriculture, 60 (15.0\%) from Education, Educational Quality, Kindergarten, and Sport education, 40 (10.0\%) from Literature, $32(8.0 \%)$ from Law and $4(1.0 \%)$ from Tourism and Hotels.

Sixteen students had an ocular problem; one of them optic atrophy, 5 students had left eye amblyopia, 3 students had right eye amblyopia, and 7 students had bilateral amblyopia. Also, the studied sample included 211 students (52.8\%) were wearing spectacles for correction of refractive errors, 53 students $(13.25 \%)$ were prescribed for wearing spectacles for 1 st time and $136(34 \%)$ with no refractive error where the median duration for wearing spectacles was 5 years. As regards the parental history there were 267 (66.8\%) students with negative history, 107 students $(26.8 \%)$ with one parent wearing spectacles and $26(6.5 \%)$ with both parents wearing spectacles. 
Profile of Refractive Errors Among Mansoura University Students EJO 2021;2:58-69

Table (1): Socio-demographic data and clinical characteristics among the studied students

\begin{tabular}{ll}
\hline Socio-demographic data & Study group $(n=400)$ \\
$\square$ clinical characteristics & \\
\hline
\end{tabular}

Age/years Mean \pm SD Min-Max

$20.35 \pm 1.21$

18.0-23.0

Gender Male Female

$192(48.0 \%)$

$208(52.0 \%)$

Residence Urban Rural

194(48.5\%)

$206(51.5 \%)$

College Medical*

Science

$129(32.2 \%)$

Engineering

$13(3.2 \%)$

$\square$ Computer information

$66(16.5 \%)$

Education*

$60(15.0 \%)$

Literature

$40(10.0 \%)$

Commerce

$37(9.2 \%)$

Agriculture

$19(4.8 \%)$

Law

$32(8.0 \%)$

Tourism and Hotels

$4(1.0 \%)$

\section{Academic year}

1styear

2ndyear

$56(14.0 \%)$

3rdyear

$129(32.2 \%)$

4thyear

$115(28.8 \%)$

5 thyear

$68(17.0 \%)$

6thyear

$25(6.2 \%)$

$7(1.8 \%)$

Systemic disease

Free

$393(98.2 \%)$

Diabetic

$6(1.5 \%)$

Rheumatoid arthritis

Ocular problem

No
L.tamblyopia

Rt. amblyopia

Bilateral amblyopia

Optic atrophy

\section{Wearing spectacles}

Yes

211(52.8\%)

No (1stspec.)

No (with no refractive error)

$136(34 \%)$

Duration of wearing spectacles

Median (Min-Max)

$5.0(1.0-14.0)$

Parent's history

Negative

One parent

$107(26.8 \%)$

Both parents

*Medical colleges include (medicine, pharmacy, dentist, veterinary and nursery) Education colleges include (Education, Educational Quality, Kindergarten education, and Sport education)

Refractive errors: the overall prevalence of refractive errors in this study was $264(66 \%)$ of the recruited students, among whom;136 (51.5\%) students were myopic,12 (4.6\%) were hyperopic, and 116 (43.9\%) were astigmatic. Moreover, 36 $(9.2 \%)$ students suffered from anisometropia. Table (2), shows details of the prevalence of refractive errors among the study group,

Table (2): Prevalence of error of refractions among the study group

\begin{tabular}{|c|c|}
\hline Error of refraction & Study group $(n=400)$ \\
\hline $\begin{array}{lr}\text { Error of } & \text { refractions } \\
\text { Refractive } & \text { errors } \\
\text { Emmetrope } & \end{array}$ & $264(66 \%)$ \\
\hline Myopic & $\begin{array}{l}136(34 \%) \\
\mathbf{1 3 6}(51.5 \%)\end{array}$ \\
\hline$\square$ Mild & $102(75 \%)$ \\
\hline$\square$ Moderate & $31(22.8 \%)$ \\
\hline$\square$ Sever & $3(2.2 \%)$ \\
\hline Hyperopic & $12(4.6 \%)$ \\
\hline Astigmatism & $116(43.9 \%)$ \\
\hline Anisometropia & $37(9.2 \%)$ \\
\hline
\end{tabular}


According to the age, among the 264 students with refractive errors, the majority of refractive errors were recorded at 20 years old in 82 students (31.1\%), followed by 21 years old $(23.1 \%)$, while most of the students with refractive errors were females that accounted for (50.4\%), and males (49.6\%). There was no significant difference in refractive error prevelance between rural residence (206 students) and urban residence (194 students). The medical faculties accounted for the highest prevalence of refractive errors $(34.1 \%)$, followed by Engineering, Computer science and

Education (15.5\%), and (14.4\%) respectively, (figure1) shows prevalence of refractive errors among different Faculties, while (figure 2) shows prevalence of different types of refractive errors among different Faculties. In terms of, the academic year, the prevalence of refractive errors was higher in the $2 \mathrm{nd}$, and 3 rd year that accounted for $(30.3 \%)$, (29.9\%) respectively. Table (3) shows relation between refractive errors and students 'characteristics.

\section{Prevalence of myopia:}

Among the 264 students with refractive errors, myopia was detected in 136 students with a prevalence of $34 \%$ from the studied sample. Further categoriztion, according to the grade of myopia showed that; low myopia was the most prevalent subtype which accounted for (75\%) from the total myopic students followed by moderate myopia $(22.79 \%)$, and high myopia which represented only $(2.2 \%)$, the prevalence of myopia was higher in the medical faculties $(36 \%)$ from the total myopic students, and myopia was more prevalent in female $(60.9 \%)$ than males $(42 \%)$.

\section{Prevalence of hyperopia:}

Among the 264 students with refractive errors, hyperopia existed in 12 students only with a prevalence of $3 \%$ from the studied sample, while the hyperopia was more prevalent in male $(5.3 \%)$ than females $(3.8 \%)$.

\section{Prevalence of astigmatism:}

Among the 264 students with refractive errors, astigmatism existed in 116 students with a prevalence of $29 \%$ out of the studied sample. The prevalence of astigmatism was higher in the medical faculties (31\%) from the total astigmatic students. 
Table (3): Relation between refractive errors and students 'characteristics

\begin{tabular}{|c|c|c|c|c|c|c|c|c|}
\hline $\begin{array}{c}\text { Students' } \\
\text { characteristics }\end{array}$ & $\begin{array}{l}\text { Total refractive } \\
\text { error(n=264) }\end{array}$ & $\begin{array}{l}\text { Total Myopic } \\
\quad(n=136)\end{array}$ & $\begin{array}{c}\text { Low } \\
(n=102)\end{array}$ & $\begin{array}{l}\text { Myopic } \\
\text { Moderate } \\
(\mathrm{n}=\mathbf{3 1})\end{array}$ & $\begin{array}{l}\text { High } \\
(n=3)\end{array}$ & $\begin{array}{c}\text { Hyperopic } \\
(\mathrm{n}=12)\end{array}$ & $\begin{array}{l}\text { Astigmatism } \\
\quad(n=116)\end{array}$ & $P$ value \\
\hline \multicolumn{9}{|l|}{ Age/years } \\
\hline 18 & $14(5.3 \%)$ & $8(57.1 \%)$ & $7(50 \%)$ & $1(7.1 \%)$ & $0(0 \%)$ & $1(7.1 \%)$ & $5(35.7 \%)$ & \multirow{6}{*}{$\begin{array}{l}0.7640 .281 \\
0.7130 .411 \\
0.0820 .704\end{array}$} \\
\hline $19-$ & $50(18.9 \%)$ & $30(60 \%)$ & $20(40 \%)$ & $9(18 \%)$ & $1(2 \%)$ & $3(6 \%)$ & $17(34 \%)$ & \\
\hline $20-$ & $82(31.1 \%)$ & $42(51.2 \%)$ & $30(36.6)$ & $11(13.4)$ & $1(1.2 \%)$ & $5(6.1 \%)$ & $35(42.7 \%)$ & \\
\hline $21-$ & $61(23.1 \%)$ & $34(55.7 \%)$ & $28(45.9)$ & $5(8.2 \%)$ & $1(1.6 \%)$ & $1(1.6 \%)$ & $26(42.6 \%)$ & \\
\hline $22-$ & $46(17.4 \%)$ & $17(37 \%)$ & $12(26.1)$ & $5(10.9 \%)$ & $0(0 \%)$ & $2(4.3)$ & $27(58.7)$ & \\
\hline $23 y$ & $11(4.2 \%)$ & $5(45.5 \%)$ & $5(45.5 \%)$ & $0(0 \%)$ & $0(0 \%)$ & $0(0 \%)$ & $6(54.5 \%)$ & \\
\hline \multicolumn{9}{|l|}{ Gender } \\
\hline Male & $131(49.6 \%)$ & $55(42 \%)$ & $46(35.1)$ & $8(6.1 \%)$ & $1(0.8 \%)$ & $7(5.3 \%)$ & $69(52.7 \%)$ & \multirow{2}{*}{$0.009^{*}$} \\
\hline Female & $133(50.4 \%)$ & $81(60.9 \%)$ & $56(42.1)$ & $23(17.3)$ & $2(1.5 \%)$ & $5(3.8 \%)$ & $47(35.3 \%)$ & \\
\hline \multicolumn{9}{|l|}{ Residence } \\
\hline Urban & $127(48.1 \%)$ & $69(54.3 \%)$ & $51(40.2)$ & $16(12.6)$ & $2(1.6 \%)$ & $5(3.9 \%)$ & $53(41.7 \%)$ & \multirow{2}{*}{0.666} \\
\hline Rural & $137(51.9 \%)$ & $67(48.9 \%)$ & $51(37.2)$ & $15(10.9)$ & $1(0.7 \%)$ & $7(5.1 \%)$ & $63(46 \%)$ & \\
\hline \multicolumn{9}{|l|}{ Faculties } \\
\hline Medical & $90(34.1 \%)$ & $49(54.4)$ & $37(41.1)$ & 11(12.2) & $1(1.1 \%)$ & $5(5.6 \%)$ & $36(40 \%)$ & \\
\hline Science & $11(4.2 \%)$ & $9(81.8 \%)$ & $7(63.6 \%)$ & $2(18.2 \%)$ & $0(0)$ & $0(0 \%)$ & $2(18.2)$ & \\
\hline Engineering & $41(15.5 \%)$ & $20(48.8)$ & $16(39 \%)$ & $4(9.8 \%)$ & $0(0 \%)$ & $1(2.4 \%)$ & $20(48.8 \%)$ & 0.6080 .141 \\
\hline$\square$ Computer & $38(14.4 \%)$ & $19(50 \%)$ & $14(36.8)$ & $4(10.5 \%)$ & $1(2.6 \%)$ & $0(0 \%)$ & $19(50 \%)$ & 0.6980 .308 \\
\hline Education & $23(8.7 \%)$ & $9(39.1 \%)$ & $7(30.4 \%)$ & $2(8.7 \%)$ & $0(0 \%)$ & $2(8.7 \%)$ & $12(52.2 \%)$ & 0.3210 .076 \\
\hline Literature & $24(9.1 \%)$ & $9(37.5 \%)$ & $8(33.3 \%)$ & $0(0 \%)$ & $1(4.2 \%)$ & $3(12.5 \%)$ & $12(50 \%)$ & 0.6230 .564 \\
\hline Commerce & $13(4.9 \%)$ & $6(46.2 \%)$ & $4(30.8 \%)$ & $2(15.4 \%)$ & $0(0 \%)$ & $0(0 \%)$ & $7(53.8 \%)$ & \\
\hline Agriculture & $24(9.1 \%)$ & $15(62.5)$ & $9(37.5 \%)$ & $6(25 \%)$ & $0(0 \%)$ & $1(4.2 \%)$ & $8(33.3 \%)$ & \\
\hline \multicolumn{9}{|l|}{ Academic year } \\
\hline 1styear & $33(12.5 \%)$ & $17(51.5 \%)$ & $14(42.4)$ & $3(9.1 \%)$ & $0(0)$ & $2(6.1 \%)$ & $14(42.4 \%)$ & \multirow{6}{*}{$\begin{array}{c}0.9000 .169 \\
0.3030 .458 \\
0.03^{*} \\
1.0\end{array}$} \\
\hline 2ndyear & $80(30.3 \%)$ & $44(55 \%)$ & $28(35 \%)$ & $14(17.5)$ & $2(2.5 \%)$ & $6(7.5 \%)$ & $30(37.5 \%)$ & \\
\hline 3rdyear & $79(29.9 \%)$ & $46(58.2 \%)$ & $39(49.4)$ & $7(8.9 \%)$ & $0(0 \%)$ & $2(2.5 \%)$ & $31(39.2 \%)$ & \\
\hline 4thyear & $46(17.4 \%)$ & $20(43.5 \%)$ & $15(32.6)$ & $4(8.7 \%)$ & $1(2.2 \%)$ & $2(4.3 \%)$ & $24(52.2 \%)$ & \\
\hline 5thyear & $21(8.0 \%)$ & $6(28.6 \%)$ & $3(14.3 \%)$ & $3(14.3 \%)$ & $0(0 \%)$ & $0(0 \%)$ & $15(71.4 \%)$ & \\
\hline 6thyear & $5(1.9 \%)$ & $3(60 \%)$ & $3(60 \%)$ & $0(0 \%)$ & $0(0 \%)$ & $0(0 \%)$ & $2(40 \%)$ & \\
\hline \multirow{3}{*}{$\begin{array}{l}\text { Parent's history } \\
\text { Negative } \\
\text { One parent Both } \\
\text { parents }\end{array}$} & $180(68.2 \%)$ & $90(33.7 \%)$ & $67(37.2)$ & $22(12.2)$ & $1(0.6 \%)$ & $7(3.9 \%)$ & $83(46.1 \%)$ & \multirow{3}{*}{$\begin{array}{c}0.4980 .282 \\
0.767\end{array}$} \\
\hline & $67(25.4 \%)$ & $39(58.2 \%)$ & $28(41.8)$ & $9(13.4 \%)$ & $2(3 \%)$ & $4(6 \%)$ & $24(35.8 \%)$ & \\
\hline & $17(6.4 \%)$ & $7(41.2 \%)$ & $7(41.2 \%)$ & $0(0 \%)$ & $0(0 \%)$ & $1(5.9 \%)$ & $9(52.9 \%)$ & \\
\hline
\end{tabular}




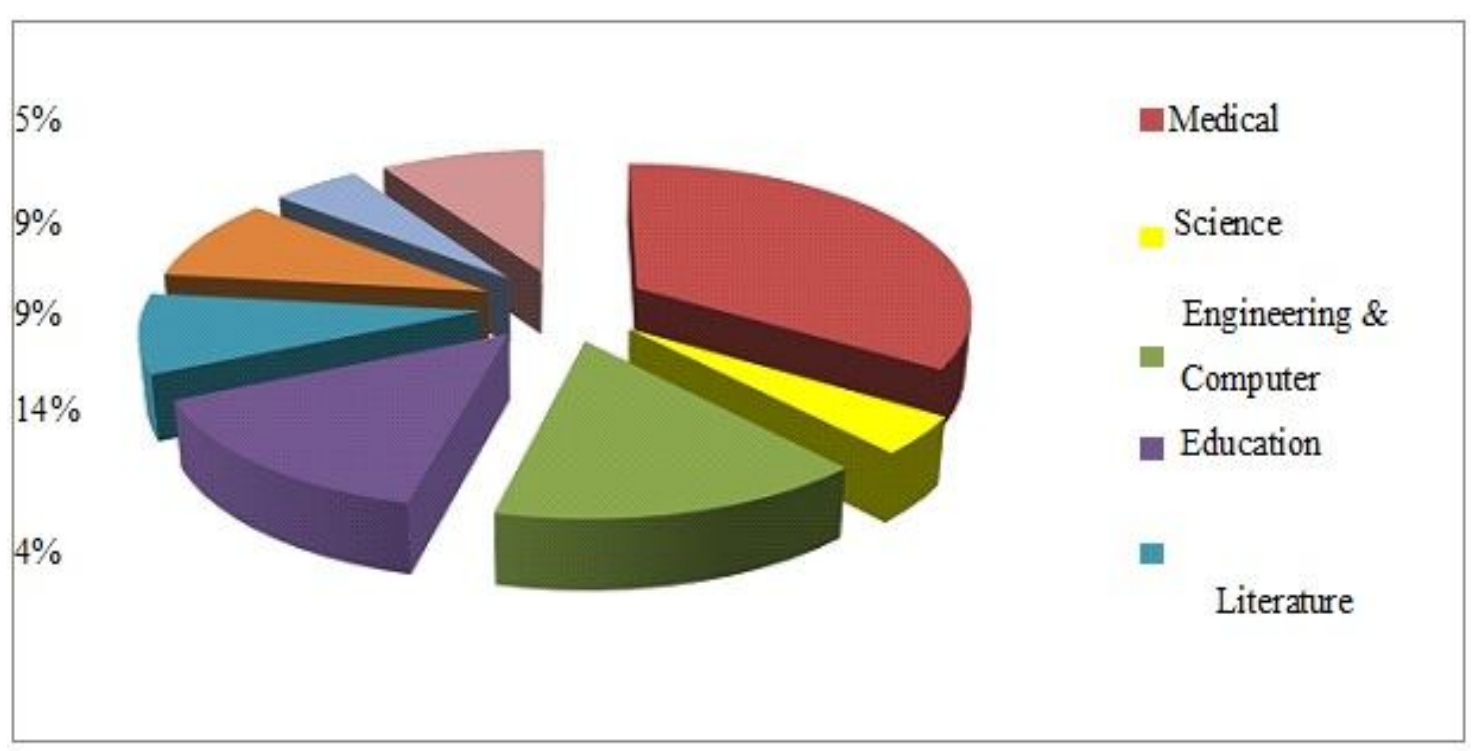

Figure (1): Prevalence of refractive errors among different Faculties

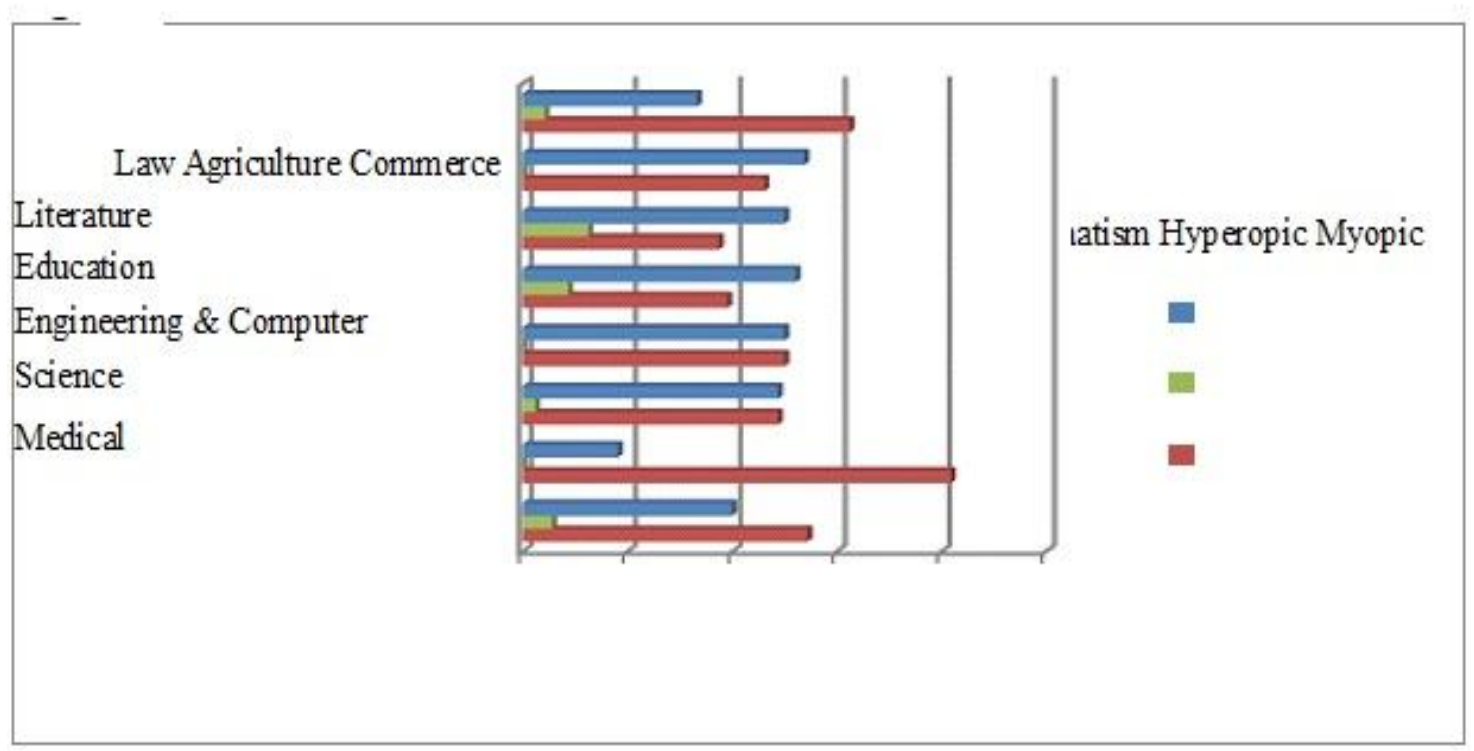

Figure (2): Prevalence of different refractive errors among faculties

\section{Discussion}

This study was performed on a large-scale data on errors of refraction among Mansoura University students in Egypt. The overall prevalence of refractive errors was $66 \%$, among that myopia and astigmatism represented $51.5 \%$ and $43.9 \%$ respectively. compared to another university-based study conducted in Assiut University in Upper Egypt, the prevalence of refractive error was only
$10.46 \%$ among those, astigmatic subjects represented $80.72 \%$ of them compared to only $16.81 \%$ for myopia. ${ }^{11}$ That difference may be explained by the time when that study was held, as it was in 2015 where several studies reported that the prevalence of refractive errors,especially myopia, has increased recently.,

In the middle east, the total prevalence of myopia (34\%), and hyperopia (3\%) in the current study were lower 
than that reported in Saudi college students (13). The prevalence of myopia was $(47.9 \%)$, while that of hyperopia was $(6.5 \%)$. In another study on medical college students ${ }^{14}$, the prevalence of myopia was estimated at $(53.7 \%)$, where hyperopia was estimated at (3.7\%). Although their definitions of both myopia and hyperopia were higher than ours $\mathrm{SE} \leq 0.75, \mathrm{SE} \geq 1.0$ respectively.

That difference might be due to the fact that refraction in Saudi students was done using non-cycloplegic refraction, where a number of studies have demonstrated that the non-cycloplegic refraction may overestimate the prevalence of myopia. ${ }^{15-18}$ therefore, in the current study we used the cycloplegic refraction. This was supported by another study made on Turkish medical students, where the prevalence of myopia was $32.9 \%$ and that of hyperopia was $16.9 \%$. In that study, the authors used cycloplegic refraction by tropicamide on whole subjects and their cut off values of myopia was defined as $\mathrm{SE} \leq 0.75 \mathrm{D}^{19}$ different than ours which was $\mathrm{SE}<0.5$.

However, hyperopia was consistent with our findings which was $\mathrm{SE}>0.5$, also in another study on Iranian college students aged 18-19 years old, the prevalence of myopia, hyperopia, and astigmatism were (42.22\%), $(5.55 \%)$ and $(32.22 \%)$, respectively ${ }^{20}$, the authors used first a non-cycloplegic autorefraction, that was followed by a non-cycloplegic refraction using a retinoscope. Finally their results were quite similar to ours, especially in the prevalence of astigmatism as our prevalence was $31.3 \%$, on the other hand the prevalence of astigmatism in this study was completely different from the referred to study on Medical Students of Saudi Arabia. ${ }^{14}$ The authors reported a prevalence of $1.2 \%$ only, may be that goes back to their definition of astigmatism (cylinder power $\geq$ 1.0)which may explainthat difference. Another metaanalysis study on Iranian University students defined astigmatism as a cylinder power $>0.5 \mathrm{D}^{20}$ Iranian made $^{(21)}$ The estimated pool prevalence of astigmatism was variable according to WHO regions; in adults, the highest estimated pool prevalence of astigmatism was in
America (45.6\%), and the lowest estimated pool prevalence was found in Africa (11.4\%),

While South-East Asia the pool prevalence of astigmatism was estimated at (44.8\%). moreover, some studies explained that high prevalence may be related to the characteristic palpebral fissure and eyelid shape in this community. ${ }^{22}$ The high prevalence of astigmatism in the current study might be due to astigmatism which highly correlated with myopia. Myopia by its turn was assoiated with higher education, hence it is expected to have that high prevalence among University students. ${ }^{23}$ However, some studies relate astigmatism to incycotorsion that occurs in the eye during near work. ${ }^{24}$

Myopia considered as a public health problem (especially in East Asian countries), different studies have described the mechanism of developing myopia as; increasing the lens thickness, also the pressure on the globe performed by the ciliary muscle, all wall increase the axial length during accommodation. Optical changes that occur during accommodation such as (increased accommodative lag or increased higher order aberration) also can change the thickness of the choroid, that may all lead to axial length changes during near work. ${ }^{25}$ additionally, myopic patients are usually more interested in performing near work, (with modern life style and the excessive use of computers for daily activities), accordingly, the engagement in outdoor activities have been decreased. ${ }^{26-28}$ Several number of studies provided evidence on the effect of outdoor activity on decreasing myopia. ${ }^{28-32}$ Also it has been reported that the severity of myopia is associated with the level of educational attainment. $^{33-35}$

According to our results, the medical faculties were associated with the highest prevalence of myopia (36\%). These findings are in agreement with Singapore medical students study ${ }^{36}$ and medical students of Saudi Arabia study. ${ }^{14}$ this supports the fact that myopia is not only a genetic disorder but is also influenced by environmental 
factors, which may have led to the development and progression of myopia. ${ }^{37,38}$

The prevalence of myopia in the current study was lower than that reported in university students' studies of Denmark and thr United States, ${ }^{39,40}$ while it is consistent with other reported studies from Europe, such as those in Portuguese university science students ${ }^{41}$, and Spain. ${ }^{42}$ It is possible that differences in prevalence of myopia across different countries may be related to ethnic variations, and different genetic predispositions. However, this study did not demonstrate any statistically significant association with familial myopia.

In this study the prevalence of hyperopia was $3 \%$, which was lower than its prevalence among the Iranian university students $7.8 \%{ }^{(43)}$ Norwegian university students ${ }^{44}$, Portuguese university students ${ }^{41}$ and Chines university student ${ }^{45}$ denoting that hyperopia is not prevalent in the Egyptian students.

Among the studied group there were $13 \%$ of total students with undiagnosed refractive error with the first time to prescribe spectacle while there were $52.8 \%$ students already wearing spectacles for a duration ranging from 1 to 14 years with a median of 5 years denoting that among the Egyptian students, the refractive errors usually presents in high school students which is also associated with the increased demand to perform near vision activities.

In the present study, the prevalence of refractive errors among the students from rural area was estimated at $51.9 \%$ which is slightly exceeding that among students from urban areas (48.1\%). This may be due to the fact that rural students spend more time on near work indoor activities. ${ }^{46}$

In our study females were associated with greater myopia risk, this agrees with the literature. Some studies attempted to provide plausible explanation to that as females may spend more time on near work activities rather than outdoor activities. ${ }^{46-48}$

Our study provided detailed data on the prevalence and associations of refractive errors among the Egyptian university students. The obvious strength of our study was to explore a relatively large number of subjects with a standardized methodology, and the use of cycloplegic refraction. The study limitation was that, the parental refractive error history was subjectively obtained via a questionnaire.

In conclusion, the present study revealed that the prevalence of myopia and astigmatism among Egyptian university students are relatively high. There is a need to attract more attention to such high prevalence to avoid the icrease of visual impairment prevalence due to refractive errors on the long term.

\section{Corresponding author}

Correspondence to Tharwat Mokbel

Email: Tharwatmokbel@yahoo.com

\section{Affiliations}

Tharwat Mokbel

Mansoura Ophthalmic Center, Mansoura University, Mansoura, Egypt.

\section{Ethics declarations}

\section{Conflict of interest}

Tharwat H. Mokbel, Ahmad Mousa, Eman Elhefney, Manal Kasem, Marwa ElKhattabi, Shereen A.AbdAllah, Ahmed Alnagdy, Doaa Shokry, all authors have no conflicts of interest that are directly relevant to the content of this review.

Funding: No sources of funding were used to conduct this review.

Reviewer disclosures: No relevant financial or other relationships to disclose.

Declaration of interest: No financial affiliations or financial involvement with any organization or entity with a financial competing with the subject matter or materials discussed in the review.

\section{References}

1.Naidoo KS, Leasher J, Bourne RR, et al. Global vision impairment and blindness due to uncorrected refractive error, 1990-2010. Optom Vis Sci. 2016;93(3):227e234. 
2. Pascolini D, Mariotti SP. Global estimates of visual impairment: 2010. Br J Ophthalmol. 2012;96(5): 614e 618.

3. Holden BA, Fricke TR, Wilson DA, et al. Global prevalence of myopia and high myopia and temporal trends from 2000 through 2050. Ophthalmology. 2016;123(5):1036e1042.

4. Williams KM, Bertelsen G, Cumberland $P$, et al. Increasing prevalence of myopia in Europe and the impact of education. Ophthalmology. 2015; 122(7):1489-1497.

5. Jacobsen N, Jensen H, Goldschmidt E. Does the level of physical activity in university students influence development and progression of Myopia? - A 2-year prospective cohort study. Invest Ophthalmol Vis Sci. 2008;49(4): 1322.

6. Rose KA, Morgan IG, Ip J, et al. Outdoor activity reduces the prevalence of myopia in children. Ophthalmology. 2008;115(8):1279-1285.

7. Khader YS, Batayha WQ, Abdul-Aziz SM, Al-ShiekhKhalil MI. Prevalence and risk indicators of myopia among school children in Amman, Jordan. East Mediterr Health J. 2006;12(3-4):434-439.

8. Onal S, Toker E, Akingol Z, et al. Refractive errors of medical students in Turkey: one-year follow-up of refraction and biometry. Optom Vis Sci. 2007;84(3):175-180.

9. Khairallah M, Kahloun R, Flaxman SR, et al. Prevalence and causes of vision loss in North Africa and the Middle East: 1990-2010. Br J Ophthalmol. 2014;98(5):605-611.

10. Saad A, El-Bayoumy BM. Environmental risk factors for refractive error among Egyptian school children. East Mediterr Health J. 2007; 13:819-828. iṣ̌p:

11. Massoud M S. H., Nassr M. A. Refractive errors among students enrolled in Assiut University, Egypt Journal of Egyptian Ophthalmological Society. 2015, $108: 21-25$
12. Daniel, W. W., \& Cross, C. L. (2018). Biostatistics: a foundation for analysis in the health sciences. Wiley.

13. Alsaif BA, Aljindan MY, Alrammah HM, Almulla MO, Alshahrani SS. Refractive errors among Saudi college students and associated risk factors. Clin Ophthalmol. 2019; 13:437-443.

14. Al-Rashidi SH, Albahouth AA, Althwini WA, Alsohibani AA, Alnughaymishi AA, Alsaeed AA, AlRashidi FH, Almatrafi S. Prevalence Refractive Errors among Medical Students of Qassim University, Saudi Arabia: Cross-Sectional Descriptive Study Macedonian Journal of Medical Sciences. 2018 May 20; 6(5):940-943

15. Morgan IG, Iribarren R, Fotouhi A, Grzybowski A. Cycloplegic refraction is the gold standard for epidemiological studies. Acta Ophthalmol. 2015; 93:581-585.

16. Fotouhi A, Morgan IG, Iribarren R, Khabazkhoob M, Hashemi H. Validity of noncycloplegic refraction in the assessment of refractive errors: the Tehran Eye Study. Acta Ophthalmol. 2012; 90:380-386.

17. Fotedar R, Rochtchina E, Morgan I, Wang JJ, Mitchell P, Rose KA. Necessity of cycloplegia for assessing refractive error in 12-year-old children: a populationbased study. Am J Oph- thalmol. 2007; 144:307-309.

18. Hashemi H, Fotouhi A, Mohammad K. The age- and gender- specific prevalences of refractive errors in Tehran: the Tehran Eye Study. Ophthalmic Epidemiol. 2004; 11:213-225.

19. Onal S, Toker E, Akingol Z, et al. Refractive errors of medical students in Turkey: one-year follow-up of refraction and biometry. Optom Vis Sci. 2007; 84:175-180.

20. Hashemi H, Pakzad R, Ali B, Yekta A, Ostadimoghaddam H, Heravian J, Yekta R, Khabazkhoob M. Prevalence of Refractive Errors in Iranian University Students in Kazerun. J Curr Ophthalmol. 2020;32(1):75-81. 
21. Hashemi H, Fotouhi A, Yekta A, Pakzad R, Ostadimoghaddam H, Khabazkhoob M. Global and regional estimates of prevalence of refractive errors: Systematic review and meta-analysis. J Curr Ophthalmol. 2017;30(1):3-22.

22. Read SA, Collins MJ, Carney LG. A review of astigmatism and its possible genesis. Clin Exp Optom. 2007;90(1):5-19

23. Dandona R, Dandona L, Srinivas M, et al. Moderate visual impairment in India: the Andhra Pradesh eye disease study. Br J Ophthalmol. 2002; 86(4):373- 377.

24. Hashemi H, Khabazkhoob M, Yekta A, et al. High prevalence of astigmatism in the 40-to 64-year-old population of Shahroud, Iran. Clin Exp Ophthalmol. 2012;40(3):247-254.

25. Hashemi H, Dadbin N, Yekta A, et al. Relation between near work and ocular biometric components. Int J Occup Hyg. 2015;7(3):153-158.

26. Ramamurthy D, Lin Chua SY, Saw SM. A review of environmental risk factors for myopia during early life, childhood and adolescence. Clin Exp Optom. 2015;98(6):497-506.

27. Hashemi H, Khabazkhoob M, Peyman A, et al. The association between residual astigmatism and refractive errors in a population-based study. JRefract Surg. 2013;29(9):624-628.

28. He M, Xiang F, Zeng Y, et al. Effect of time spent outdoors at school on the development of myopia

37. Fan DC, Lam DS, Lam RF, Lau JT, Chiong KS, Cheung EY et al. Prevalence, incidence, and progression of myopia of school children in Hong Kong. Invest Ophthalmol Vis Sci. 2004; 45: 1071-1075.

38. Ling SL, Chen AJ, Rajan U, Cheah WM. Myopia in 10year-old children: a case control study. Singapore Med J .1990; 31: 472-473.

39. Loman, J. BA, Quinn G. E., Kamoun L., Ying G.H. Maguire M. G., David Hudesman, BA, Richard A. Stone. Darkness and Near Work Myopia and Its Progression in Third-year Law Students. Ophthalmology. 2002; 109:5 among children in China: a randomized clinical trial. JAMA. 2015;314(11):1142-1148.

29. Pan CW, Ramamurthy D, Saw SM. Worldwide prevalence and risk factors for myopia. Ophthalmic Physiol Opt. 2012;32(1):3-16.

30. Jin JX, Hua WJ, Jiang X, et al. Effect of outdoor activity on myopia onset and progression in schoolaged children in northeast China: the Sujiatun Eye Care Study. BMC Ophthalmol. 2015; 15:73.

31. Ashby R, Ohlendorf A, Schaeffel F. The effect of ambient illuminance on the development of deprivation myopia in chicks. Invest Ophthalmol Vis Sci. 2009;50(11):5348-5354.

32. Ashby RS, Schaeffel F. The effect of bright light on lens compensation in chicks. Invest Ophthalmol Vis Sci. 2010;51(10):5247-5253.

33. Au Eong KG, Tay TH, Lim MK. Race, culture and myopia in 110,236 young Singaporean males. Singapore Med J .1993; 34:29-32.

34. Saw SM, Katz J, Schein OD, Chew SJ, Chan TK. Epidemiology of myopia. Epidemiol Rev .1996; 18:175-87.

35. Rosner M, Belkin M. Intelligence, education and myopia in males. Arch Ophthalmol 1987; 105:150811.

36. Woo WW, Lim KA, Yang H, Lim XY, Liew F, Lee YS, Saw SM. Refractive errors in medical students in Singapore. Singapore Med J. 2004;45(10):470-4.

40. Fledelius HC. Myopia profile in Copenhagen medical students 1996-98. refractive stability over a century is suggested. Acta Ophthalmol Scand. 2000 78(5):501-5.

41. Jorge J, Almeida JB, Parafita MA. Refractive, biometric and topographic changes among Portuguese university science students: a 3-year longitudinal study. Ophthalmic Physiol Optic. 2007;27(3):287-294.

42. Montes-Mico, R. and Ferrer-Blasco, T. Distribution of refractive errors in Spain. Doc. Ophthalmol.200; 101, 2533. 
43. H. Hashemi, M. Khabazkhoob, N. Yazdani, et al.The prevalence of refractive errors among iranian university students. Iranian J Ophthalmol.2014;26:(3) 129-135

44. Kinge B, Midelfart A. Refractive changes among Norwegian university students a three-year longitudinal study. Acta Ophthalmol Scand.1999; 77(3):302-305.

45. Wei S, Sun Y, Li S, Hu J, Yang X, Lin C, Cao K, Du J, Guo J, Li H, Wang N. Refractive Errors in University Students in Central China: The Anyang University Students Eye Study. Invest Ophthalmol Vis Sci. 2018;59(11):4691-4700.
46. He M, Zeng J, Liu Y, Xu J, Pokharel GP, Ellwein LB. Refractive error and visual impairment in urban children in Southern China. Invest Ophthalmol Vis Sci. 2004; 45:793-799.

47. Saw SM, Chan YH, Wong WL, et al. Prevalence and risk factors for refractive errors in the Singapore Malay Eye Survey. Ophthalmology. 2008; 115:1713-1719.

48. You QS, Wu LJ, Duan JL, et al. Prevalence of myopia in school children in greater Beijing: the Beijing Childhood Eye Study. Acta Ophthalmologica. 2014;92: 398-406. 